\title{
The impact of thiopurines on surgical outcomes in inflammatory bowel disease: do they make a difference? Vivek Chhaya and Richard Pollok*
}

Address: Department of Gastroenterology, St George's Hospital University NHS Trust, Blackshaw Road, London SW17 0QT

*Corresponding author: Richard Pollok (richard.pollok@nhs.net)

Fl000Prime Reports 2013, 5:50 (doi:10.12703/P5-50)

This is an open-access article distributed under the terms of the Creative Commons Attribution-Non Commercial License (http://creativecommons.org/licenses/by-nc/3.0/legalcode), which permits unrestricted use, distribution, and reproduction in any medium, provided the original work is properly cited. You may not use this work for commercial purposes.

The electronic version of this article is the complete one and can be found at: http://f $1000 . c o m / p r i m e /$ reports/m/5/50

\begin{abstract}
Ulcerative colitis and Crohn's disease together are known as inflammatory bowel disease (IBD). Surgery is considered for more severe disease and is a dreaded consequence for patients. Thiopurines have proven efficacy in the induction and maintenance of remission of IBD, but the long-term need for surgery remains uncertain with conflicting results from the available studies. The timing and duration of thiopurines also appears to play a pivotal role in the management of these conditions and may also affect the need for surgery. Data from Denmark, Canada, Hungary and the UK appear to suggest a reduction in surgery rates prior to the introduction of anti-tumor necrosis factor (TNF) therapy. The authors aim to review the more recent literature evaluating the surgery rates in IBD and changes in disease trends over time. We ask whether increasing thiopurine prescribing has had an effect on the surgery rates in the era of biologic therapy and whether more aggressive treatment approaches have altered the natural history of IBD.
\end{abstract}

\section{Introduction}

Crohn's disease and ulcerative colitis are part of a group of conditions referred to as IBD [1]. The relapsing and remitting nature of IBD often causes severely debilitating disease, which has an impact on quality of life $[2,3]$. The etiology has not been established but there is an exaggerated immune response that leads to diffuse mucosal inflammation and symptoms $[1,4,5]$.

Corticosteroids are often used to suppress the inflammatory response and induce remission [6-9]. Unfortunately, steroids have no proven role in maintaining remission [10]. Surgery is often required for cases refractory to medical therapy, but has associated morbidity and mortality $[11,12]$. We will review the impact of thiopurines, a group of drugs used extensively in the induction of remission and maintenance for both Crohn's disease and ulcerative colitis, and ask if they have any impact on the need for surgery in IBD.

\section{Thiopurines}

Thiopurines (azathioprine and its metabolite 6-mercaptopurine) are immunomodulatory agents widely used in inflammatory conditions. Azathioprine is initially converted to 6-mercaptopurine, which undergoes several enzymatic pathways and is transformed to its active metabolite, 6-thioguanine nucleotides (6-TGN). 6-TGN interferes with DNA and RNA synthesis, subsequently inhibiting lymphocyte proliferation, which leads to a decreased immune response [13-15].

\section{Ulcerative colitis}

Ulcerative colitis is characterised by persistent bloody diarrhea or rectal bleeding and is restricted to the colon [16]. Extensive disease is associated with more severe symptoms [16,17]. Mild symptoms are managed with 5-aminosalicylates (5-ASA) [18]. Corticosteroids are the mainstay of acute treatment for moderate to severe disease as highlighted by the original trials conducted by 
Truelove in 1955 [9]. Between 7 and 22\% of sufferers experience recurring symptoms or steroid-dependent disease [19]. Surgery, in the form of colectomy, has remained the only option for disease resistant to medical therapy $[20,21]$. Immunomodulators and thiopurines in particular have been advocated to reduce the need for colectomy and the requirement for repeated courses of corticosteroids [19]. Cyclosporin, infliximab and adalimumab have also been evaluated (mainly in the context of acute severe ulcerative colitis in hospitalised patients) but will not be discussed further in this review.

The majority of controlled trials evaluating the use of thiopurines in ulcerative colitis were undertaken more than 30 years ago [22-26]. More recently, in 2006, Ardizzone et al. performed a randomized, investigator blind, controlled trial comparing azathioprine and 5-ASA for the treatment of steroid-dependent ulcerative colitis [19]. They found azathioprine therapy to be significantly more effective than 5-ASA therapy in the induction of clinical and endoscopic remission, and steroid requirement was reduced in the azathioprine group. In 2012, a review by the Cochrane collaboration compared six controlled trials evaluating thiopurines against placebo or thiopurines against 5-ASAs or methotrexate [27]. They concluded that azathioprine was superior to placebo in the maintenance of remission in ulcerative colitis and that more studies were needed to compare azathioprine to standard therapy.

However, none of these studies have evaluated the effects of thiopurines on the need for surgery in ulcerative colitis. Solberg et al. investigated the course of ulcerative colitis during a 10 year follow up period and attempted to identify prognostic risk factors based on the information gathered at diagnosis [28]. They reported a cumulative colectomy rate at 10 years of $9.8 \%$. They also reported on azathioprine usage of $7 \%$ but did not analyse its effect on colectomy. Targownik et al. reported in 2012 on the epidemiology of colectomy in ulcerative colitis [21]. Their primary outcome showed a lower cumulative incidence of colectomy in ulcerative colitis compared to previous studies. However, in subgroup analysis, they reported that patients using greater than 16 weeks of thiopurines were less likely to undergo colectomy at 2 years than those using less than 16 weeks of therapy $(5.6 \%$ versus $12.8 \%, \mathrm{p}=0.0035)$. Unfortunately, only 73 patients were in this subgroup with 20 receiving less than 16 weeks of thiopurines compared to 53 receiving greater than 16 weeks of thiopurines. Kaplan et al. compared emergent versus elective colectomy rates for patients hospitalised for a flare of ulcerative colitis [29]. They concluded that the rates of elective colectomy significantly dropped during their study period, whereas the emergent colectomy rates remained constant. In their subgroup analysis, they noted a significant increase (by 20\%) in thiopurine prescribing between 1997 and 2009 (odds ratio [OR] 1.20; 95\% confidence interval [CI] $1.14-1.27$ ) and inferred that the increase may have had an impact on the decline in colectomy rates. This should be interpreted with caution as they did not observe a clear inflection point correlating with the changes, numbers were small and the association was inferred. Williet et al. investigated the cumulative incidence of colectomy and the impact of medication prescribing on the need for colectomy [30]. In a single referral centre, they reviewed 151 incident cases of ulcerative colitis and found that $14 \%$ underwent colectomy during their follow up period between 2000 and 2010. The cumulative probabilities for colectomy at 1 and 5 years from diagnosis were 1.3\% and 13.5\% respectively. The probability of receiving azathioprine at 5 years of follow up was $48.9 \%$. Azathioprine use was not associated with a reduced risk for colectomy in their univariate analysis and neither was infliximab use. Receiver operating characteristic (ROC) analysis did not identify a significant threshold for the duration of azathioprine with respect to colectomy. The only predictor of colectomy in this study was previous cyclosporin use with an OR of 4.41 (95\% CI: 1.75 $11.13, \mathrm{p}=0.002$ ). Overall, the more recently evaluated studies suggest 10 year colectomy rates in the region of $10 \%$ for ulcerative colitis. This is a significant decrease compared to historical cohorts where the 10-year rates quoted were as high as $30 \%[31,32]$ but whether this effect can be solely attributable to thiopurine use needs to be proven in an era of biological therapy where these effects may be confounded.

The Active Ulcerative Colitis Trial, (ACT)-1 and ACT-2, was one of the first trials in ulcerative colitis to show that patients with moderate to severe disease receiving infliximab had improved clinical outcomes, compared to those receiving placebo through a follow up period of 54 and 30 weeks respectively. However, the long term impact of infliximab on colectomy and its use with thiopurines in ulcerative colitis remains unknown and long term data are awaited [33-35].

\section{Crohn's disease}

Crohn's disease is characterised by patchy, transmural inflammation affecting any part of the gastrointestinal tract with systemic features such as malaise, anorexia and weight loss [36]. The natural history of the disease is such that there is frequently a progression from an inflammatory phenotype to a stricturing or penetrating one $[17,36]$. Perianal complications are a frequent manifestation of Crohn's disease and result in significant 
morbidity [2]. Surgery is often reserved for patients with complicated or severe disease and, although it is not curative, remains important in the management of Crohn's disease [37]. In general, Crohn's disease is a more aggressive disease than ulcerative colitis, with a greater need for surgery and disease modification with immunomodulators like thiopurines.

Several studies have evaluated the natural history of Crohn's disease using historical cohorts and healthcare records on hospitalisation and surgery to establish phenotypic characteristics of disease severity and poor outcomes [37]. Early studies, such as those from Oxford between 1938 and 1970, showed that up to 74\% of patients required surgery for Crohn's disease [38]. A population-based cohort from Copenhagen County between 1962 and 1987, reported surgery rates in the first year of diagnosis to be $35 \%$. The cumulative probability of surgery was $61 \%$ after 10 years and $82 \%$ after 20 years $[39,40]$. An updated cohort assessing incident cases from 2003 to 2005 reports a reduction in the surgery rate within the first year after diagnosis to $12 \%$ [41]. In the UK, a population-based study from Cardiff reported that $43 \%$ of patients underwent surgery. After dividing the cohort into eras, the authors noted a significant decrease in the need for surgery during their follow-up period between 1986 and 2003 [42]. These studies appear to suggest a decline in surgery rates over time, which are associated with earlier and more frequent use of thiopurines, but may also reflect other changes in medical and surgical management.

In a recent population-based study from Manitoba, the cumulative incidence for surgery at 1, 5, 10 and 20 years after diagnosis was $13 \%, 24 \%, 32 \%$ and $39 \%$ respectively [43]. They identified a decrease in the cumulative incidence rates of surgery by era of diagnosis. However, another population-based cohort from Stockholm County between 1955 and 1974, reported rates of surgery of 30\%, $50 \%$ and $60 \%$ at 5, 10 and 15 years respectively, and this did not change significantly when a more recent cohort was evaluated $[44,45]$. In a French referral centre study between 1978 and 2002, the 5 year cumulative risk of surgery remained stable over time despite an increase in immunomodulator use [46]. However, a major limitation of this study was the fact that a large proportion of patients proceeded to surgical resection prior to treatment with thiopurines, or had early surgery within 3 months of starting thiopurines [47]. Overall, it appears that up to half of patients with Crohn's disease will have undergone surgery 10 years after diagnosis [37].

We have conflicting evidence that thiopurines may alter the natural history of Crohn's disease by reducing the requirement for surgery. The studies from Denmark, Manitoba and Cardiff do suggest that patients diagnosed in a more recent era are likely to undergo surgery less frequently, whereas the French and Swedish studies do not suggest a change in surgery rates over time.

The timing and duration of thiopurines may have an impact on the surgical outcome [13]. It has been suggested that the majority of patients are likely to have an inflammatory phenotype at diagnosis, which changes over time to a more stricturing and penetrating behavior later in the disease course [48]. This has led to the notion that thiopurines and other immunomodulators used early in the disease course may alter the natural history of the disease, before the development of complications that may occur in up to three quarters of patients during their lifetime [13]. This was initially suggested by Markowitz et al. in 2000 from a paediatric study [49]. Further evidence to support early use of thiopurines to reduce the need for surgery came from an historical cohort from the Mayo clinic in 2009 by Picco and colleagues [50]. In a retrospective referral centre observational study (investigating the time to first surgery in patients treated with medical therapies), they found a 59\% decrease in the risk of first surgery in patients treated with thiopurines for at least 6 months duration (hazard ratio [HR] 0.41, 95\% CI $0.21-0.81, \mathrm{P}=0.011$. In a population-based inception cohort from Western Hungary between 1997 and 2009, azathioprine exposure was $45.8 \%$ [51]. Lakatos et al. divided a regional cohort by year of diagnosis and found that exposure to azathioprine increased in patients diagnosed later during their follow-up period. They also demonstrated a reduction in surgical rates that was independently associated with increased and earlier azathioprine use. Ramadas et al. reported that early thiopurine use within the first year of diagnosis reduced the need for intestinal resection by $53 \%$ (HR 0.47 , CI 0.27 to $0.79, \mathrm{p} 0.005$ ), adding further evidence for the early use of thiopurines in Crohn's disease [42]. Peyrin-Biroulet et al. conducted an observational study of a referral centre cohort and also concluded that treatment with azathioprine for less than 45 days increased the risk of intestinal surgery (HR 2.0, 95\% CI: 1.20 - 3.34, p 0.008) [52].

An increasing trend in the use of immunomodulators amongst IBD patients has been demonstrated in a recent paper assessing prescribing patterns amongst members of the Kaiser Permanente health care system in Northern California [53]. Herrinton et al. report a decline in hospitalisation rates with no change in the surgery rate for Crohn's disease, but a decline in both hospitalisation and surgery in ulcerative colitis. This coincides with the increasing use of immunomodulator therapy, mainly thiopurines, in both Crohn's disease and ulcerative 
colitis. The change in these rates may also reflect the use of biological therapy in Crohn's disease. However, biological therapy was not widely available for use in ulcerative colitis at the time of study. In a recent study, this trend in Crohn's disease has also been documented in a national UK-based cohort study using the General Practice Research Database (GPRD) [54]. Incident cases were identified retrospectively between 1989 and 2005 and a significant (65\%) decline in first intestinal resection rates was noted during this period. They also found an increasing trend in thiopurine prescribing during this time period and also noted earlier use within the same time frame.

In general, there has been an increase in the use of thiopurines in Crohn's disease with evidence to suggest benefits of earlier and more prolonged duration of use and this has been associated with a concurrent reduction in intestinal surgery. The evidence from recent cohort studies on the impact of thiopurines on surgery is generally positive but remains somewhat conflicting. A meta-analysis of the reported studies would be useful.

Infliximab has been known to improve clinical outcomes in Crohn's disease for the last 15 years [55] and has been approved by the US Food and Drug Administration (FDA) since 1998, but the long term risk of requiring surgery beyond a year of follow up has not been widely reported [37]. The use of concomitant immunosuppression (i.e. infliximab and a thiopurine) has also been shown to be more effective than conventional therapy (step-up top-down) [56] and is also significantly better for inducing steroid-free remission and mucosal healing than azathioprine alone in azathioprine naïve patients (study of biologic and immunomodulator naïve patients in Crohn's disease - SONIC) [57]. This may have an impact on the reported decline in surgery rates for Crohn's disease.

\section{Perianal Crohn's disease}

Crohn's disease may be complicated by perianal disease, which can lead to faecal incontinence, abscess formation and stricturing [58]. The management of perianal lesions is complex, with surgery often performed in conjunction with medical therapy. The presence of perianal lesions at diagnosis has been identified as a marker for an unfavorable clinical course in Crohn's disease [59-61] and has also been identified as a predictor for disease behavior change from an inflammatory to a stricturing or penetrating phenotype, over time [62]. A meta-analysis reported on fistula closure as a secondary endpoint and found that $54 \%$ of 70 patients treated with thiopurines demonstrated fistula healing versus $21 \%$ of controls [63]. However, there have been no controlled trials where the primary endpoint was the effect of thiopurines on fistula closure in patients with Crohn's disease [64]. Dejaco et al. showed that patients treated with antibiotics failed to maintain an initial response to treatment unless the antibiotics were used in combination with azathioprine [65]. Lecomte et al. presented data on the effect of thiopurines on patients with perianal lesions in Crohn's disease [66]. 94 patients were treated with thiopurines for a minimum duration of 6 months and improvement was noted in 27 patients (29\%). This suggests that perianal lesions do respond to thiopurines but not as well as intestinal disease does.

Many of the population-based studies report on the proportion of patients with perianal Crohn's disease and the fact that the presence of perianal lesions increased the risk of surgery [67] but there are no studies investigating the effect of thiopurines on the need for perianal surgery. Furthermore, perianal Crohn's disease often requires the use of antibiotics and, more recently, anti-TNF treatment in conjunction with thiopurines, which has changed the management of Crohn's disease dramatically $[55,68,69]$. It is now unlikely that thiopurines alone would be used as monotherapy to treat perianal Crohn's disease and controlled trials would be unethical. The role of thiopurines in treating perianal Crohn's disease in the biologic era remains uncertain and warrants further research.

\section{Conclusions}

Referral centre studies prior to the use of thiopurines suggest high rates of surgery in Crohn's disease. Comparison to more contemporary data from population-based and referral centre studies suggest greatly reduced surgery rates. During the same period, thiopurine usage has increased over time, according to cohort studies evaluating the trends in disease and natural history of IBD. There is also increasing evidence to suggest the early use of thiopurines, prior to the development of complications in Crohn's disease, may prevent disease progression. Overall, the majority of studies report a declining trend in surgical resection rates for Crohn's disease, but a minority of conflicting studies have not demonstrated this pattern. There is also conflicting evidence on whether thiopurines affect the natural history of ulcerative colitis and the need for colectomy. None of the studies to date evaluate its use as a primary outcome in ulcerative colitis where the endpoint is colectomy. Similarly, there is a paucity of data on the effects of thiopurines on perianal Crohn's disease, which requires a multidisciplinary approach and a combination of treatments including antibiotics, immunomodulators and biologics. Further studies are warranted.

In conclusion, thiopurines have a definite role in the management of ulcerative colitis and Crohn's disease 
and are a valuable tool in the armory of a Gastroenterologist. The majority of studies suggest a decrease in surgery rates in IBD associated with increased and earlier use of azathioprine. In our opinion, thiopurines in tandem with newer biological agents do seem to have an effect on resection rates, but surgery is still required for many patients. Whether more aggressive treatment approaches in IBD will affect the long-term need for surgery and ultimately, alter the natural history of these conditions remains unknown.

Our practice is to consider early introduction of thiopurines in patients with moderate to severe disease requiring early or repeated courses of steroids. There should be a lower threshold for the introduction of thiopurines in patients with Crohn's disease who are under 18 at diagnosis, have perianal disease or have isolated proximal small bowel disease since these are adverse prognostic markers. The timing of thiopurine discontinuation is contentious. A discussion after 3-5 years of quiescent disease should be considered but studies investigating thiopurine withdrawal have suggested a higher rate of relapse even after prolonged quiescence $[70,71]$. The benefits of treatment need to be tempered by a discussion of the small but significant increased risk of lymphoproliferative disorders associated with thiopurines [72]. The decision to withdraw treatment requires careful consideration on an individual basis and is often guided by the patient's wishes.

\section{Abbreviations \\ 5-ASA, 5-aminosalicylate; 6-TGN, 6-thioguanine nucleo- tide; ACT, Active Ulcerative Colitis Trial; $\mathrm{CI}$, confidence interval; FDA, US Food and Drug Administration; GPRD, General Practice Research Database; HR, hazard ratio; IBD, inflammatory bowel disease; OR, odds ratio; ROC, receiver operating characteristic; SONIC, study of bio- logic and immunomodulator naïve patients in Crohn's disease.}

\section{Disclosures}

The authors declare that they have no disclosures.

\section{References}

I. Lewis JD, Aberra FN, Lichtenstein GR, Bilker WB, Brensinger C, Strom BL: Seasonal variation in flares of inflammatory bowel disease. Gastroenterology 2004, 126:665-73.

2. Schwartz DA, Herdman CR: Review article: The medical treatment of Crohn's perianal fistulas. Aliment Pharmacol Ther 2004, 19:953-67.

3. Mahadev S, Young JM, Selby W, Solomon MJ: Quality of life in perianal Crohn's disease: what do patients consider important? Dis Colon Rectum 20I I, 54:579-85.

$$
\text { FlOOOPrime }
$$

4. Fiocchi C: Inflammatory bowel disease: etiology and pathogenesis. Gastroenterology 1998, I I5: 182-205.

5. Monteleone I, Vavassori P, Biancone L, Monteleone G, Pallone F: Immunoregulation in the gut: success and failures in human disease. Gut 2002, 50(Suppl 3):III60-4.

6. Sherlock ME, Seow $\mathrm{CH}$, Steinhart $\mathrm{AH}$, Griffiths $\mathrm{AM}$ : Oral budesonide for induction of remission in ulcerative colitis. Cochrane Database Syst Rev 2010:CD007698.

7. Benchimol El, Seow $\mathrm{CH}$, Steinhart $\mathrm{AH}$, Griffiths AM: Traditional corticosteroids for induction of remission in Crohn's disease. Cochrane Database Syst Rev 2008:CD006792.

8. Seow $\mathrm{CH}$, Benchimol El, Griffiths $\mathrm{AM}$, Otley $\mathrm{AR}$, Steinhart $\mathrm{AH}$ : Budesonide for induction of remission in Crohn's disease. Cochrane Database Syst Rev 2008:CD000296.

9. Truelove SC, Witts LJ: Cortisone in ulcerative colitis; final report on a therapeutic trial. $\mathrm{Br}$ Med J 1955, 2:104I-8.

10. Punati J, Markowitz J, Lerer T, Hyams J, Kugathasan S, Griffiths A, Otley A, Rosh J, Pfefferkorn M, Mack D, Evans J, Bousvaros A, Moyer MS, Wyllie R, Oliva-Hemker M, Mezoff A, Leleiko N, Keljo D, Crandall $W$ : Effect of early immunomodulator use in moderate to severe pediatric Crohn disease. Inflamm Bowel Dis 2008, 1 4:949-54.

II. Ellis MC, Diggs BS, Vetto JT, Herzig DO: Trends in the surgical treatment of ulcerative colitis over time: increased mortality and centralization of care. World J Surg 20I I, 35:67I-6.

12. Kaplan GG, McCarthy EP, Ayanian JZ, Korzenik J, Hodin R, Sands BE: Impact of hospital volume on postoperative morbidity and mortality following a colectomy for ulcerative colitis. Gastroenterology 2008, 134:680-7.

13. Etchevers MJ, Aceituno M, Sans M: Are we giving azathioprine too late? The case for early immunomodulation in inflammatory bowel disease. World J Gastroenterol 2008, I4:55 I2-8.

14. Dubinsky MC: Azathioprine, 6-mercaptopurine in inflammatory bowel disease: pharmacology, efficacy, and safety. Clin Gastroenterol Hepatol 2004, 2:731-43.

15. Siegel CA, Sands BE: Review article: practical management of inflammatory bowel disease patients taking immunomodulators. Aliment Pharmacol Ther 2005, 22:1-16.

16. Baumgart DC, Sandborn WJ: Inflammatory bowel disease: clinical aspects and established and evolving therapies. Lancet 2007, 369:1641-57.

17. Satsangi J, Silverberg MS, Vermeire S, Colombel J: The Montreal classification of inflammatory bowel disease: controversies, consensus, and implications. Gut 2006, 55:749-53.

18. Hanauer SB: Medical therapy for ulcerative colitis 2004. Gastroenterology 2004, I 26: I582-92.

19. Ardizzone S, Maconi G, Russo A, Imbesi V, Colombo E, Bianchi Porro G: Randomised controlled trial of azathioprine and 5-aminosalicylic acid for treatment of steroid dependent ulcerative colitis. Gut 2006, 55:47-53.

FlOOOPrime

RECOMMENDED

20. Cohen JL, Strong SA, Hyman NH, Buie WD, Dunn GD, Ko CY, Fleshner PR, Stahl TJ, Kim DG, Bastawrous AL, Perry WB, Cataldo PA, Rafferty JF, Ellis CN, Rakinic J, Gregorcyk S, Shellito PC, Kilkenny JW, Ternent CA, Koltun W, Tjandra JJ, Orsay CP, Whiteford MH, Penzer JR: Practice parameters for the surgical treatment of ulcerative colitis. Dis Colon Rectum 2005, 48: 1997-2009.

21. Targownik LE, Singh H, Nugent Z, Bernstein CN: The epidemiology of colectomy in ulcerative colitis: results from a populationbased cohort. Am J Gastroenterol 2012, 107:1228-35.

\section{FlOOOPrime}

RECOMMENDED

22. Jewell DP, Truelove SC: Azathioprine in ulcerative colitis: an interim report on a controlled therapeutic trial. $\mathrm{Br}$ Med J 1972 , I:709-12. 
23. Jewell DP, Truelove SC: Azathioprine in ulcerative colitis: final report on controlled therapeutic trial. $\mathrm{Br}$ Med J 1974, 4:627-30.

24. Hawthorne AB, Logan RF, Hawkey CJ, Foster PN, Axon AT, Swarbrick ET, Scott BB, Lennard-Jones JE: Randomised controlled trial of azathioprine withdrawal in ulcerative colitis. BMJ 1992, 305:20-2.

25. Kirk AP, Lennard-Jones JE: Controlled trial of azathioprine in chronic ulcerative colitis. Br Med J (Clin Res Ed) 1982, 284:I29|-2.

26. Rosenberg JL, Wall AJ, Levin B, Binder HJ, Kirsner JB: A controlled trial of azathioprine in the management of chronic ulcerative colitis. Gastroenterology 1975, 69:96-9.

27. Timmer A, McDonald JWD, Tsoulis DJ, Macdonald JK: Azathioprine and 6-mercaptopurine for maintenance of remission in ulcerative colitis. Cochrane Database Syst Rev 2012, 9:CD000478.

\section{FlOOOPrime \\ RECOMMENDED}

28. Solberg IC, Lygren I, Jahnsen J, Aadland E, Høie O, Cvancarova M, Bernklev T, Henriksen M, Sauar J, Vatn MH, Moum B: Clinical course during the first 10 years of ulcerative colitis: results from a population-based inception cohort (IBSEN Study). Scand J Gastroenterol 2009, 44:431-40.

\section{FlOOOPrime} RECOMMENDED

29. Kaplan GG, Seow CH, Ghosh S, Molodecky N, Rezaie A, Moran GW, Proulx M, Hubbard J, MacLean A, Buie D, Panaccione R: Decreasing colectomy rates for ulcerative colitis: a population-based time trend study. Am J Gastroenterol 2012, 107:1879-87.

\section{FlOOOPrime
RECOMMENDED}

30. Williet N, Pillot C, Oussalah A, Billioud V, Chevaux J, Bresler L, Bigard M, Gueant J, Peyrin-Biroulet L: Incidence of and impact of medications on colectomy in newly diagnosed ulcerative colitis in the era of biologics. Inflamm Bowel Dis 2012, I 8: 164 I-6.

\section{FlOOOPrime}

\section{RECOMMENDED}

31. Farmer RG, Easley KA, Rankin GB: Clinical patterns, natural history, and progression of ulcerative colitis. A long-term follow-up of I I I 6 patients. Dig Dis Sci 1993, 38: I I37-46.

32. Leijonmarck CE, Persson PG, Hellers G: Factors affecting colectomy rate in ulcerative colitis: an epidemiologic study. Gut 1990, 31:329-33.

33. Sandborn WJ, Rutgeerts P, Feagan BG, Reinisch W, Olson A, Johanns J, Lu J, Horgan K, Rachmilewitz D, Hanauer SB, Lichtenstein GR, de Villiers WJS, Present D, Sands BE, Colombel JF: Colectomy rate comparison after treatment of ulcerative colitis with placebo or infliximab. Gastroenterology 2009, I37: | 250-60; quiz |520.

34. Colombel JF, Rutgeerts $\mathrm{P}$, Reinisch W, Esser D, Wang $\mathrm{Y}$, Lang $\mathrm{Y}$, Marano CW, Strauss R, Oddens BJ, Feagan BG, Hanauer SB, Lichtenstein GR, Present D, Sands BE, Sandborn WJ: Early mucosal healing with infliximab is associated with improved longterm clinical outcomes in ulcerative colitis. Gastroenterology 201।, 141:1194-201.

\section{FlOOOPrime}

RECOMMENDED

35. Rutgeerts P, Sandborn WJ, Feagan BG, Reinisch W, Olson A, Johanns J, Travers S, Rachmilewitz D, Hanauer SB, Lichtenstein GR, de Villiers WJS, Present D, Sands BE, Colombel JF: Infliximab for induction and maintenance therapy for ulcerative colitis. $N$ Engl J Med 2005, 353:2462-76.

\section{FlOOOPrime
RECOMMENDED}

36. Mowat C, Cole A, Windsor A, Ahmad T, Arnott I, Driscoll R, Mitton S, Orchard T, Rutter M, Younge L, Lees C, Ho G, Satsangi J, Bloom S: Guidelines for the management of inflammatory bowel disease in adults. Gut 2011, 60:571-607.
37. Bernstein CN, Loftus EV, Ng SC, Lakatos PL, Moum B: Hospitalisations and surgery in Crohn's disease. Gut 2012, 61 :622-9.

\section{FIOOOPrime
RECOMMENDED}

38. Truelove SC, Pena AS: Course and prognosis of Crohn's disease. Gut 1976, I7:|92-20|

39. Binder V, Hendriksen C, Kreiner S: Prognosis in Crohn's diseasebased on results from a regional patient group from the county of Copenhagen. Gut 1985, 26:146-50.

40. Munkholm P, Langholz E, Davidsen M, Binder V: Intestinal cancer risk and mortality in patients with Crohn's disease. Gastroenterology 1993, 105:1716-23.

4I. Vind I, Riis L, Jess T, Knudsen E, Pedersen N, Elkjaer M, Bak Andersen I, Wewer V, Nørregaard P, Moesgaard F, Bendtsen F, Munkholm P: Increasing incidences of inflammatory bowel disease and decreasing surgery rates in Copenhagen City and County, 2003-2005: a population-based study from the Danish Crohn colitis database. Am J Gastroenterol 2006, I 0 I: | 274-82.

42. Ramadas AV, Gunesh S, Thomas GAO, Williams GT, Hawthorne AB: Natural history of Crohn's disease in a population-based cohort from Cardiff (1986-2003): a study of changes in medical treatment and surgical resection rates. Gut 2010 , 59: $1200-6$.

\section{FlOOOPrime RECOMMENDED}

43. Nguyen GC, Nugent Z, Shaw S, Bernstein CN: Outcomes of patients with Crohn's disease improved from 1988 to 2008 and were associated with increased specialist care. Gastroenterology 201 I, I41:90-7.

44. Hellers G: Crohn's disease in Stockholm County from 19551974. A study of epidemiology, results of surgical treatment and long term prognosis. Acta Chir Scand Suppl 1979, 49:1-84.

45. Bernell O, Lapidus A, Hellers G: Risk factors for surgery and postoperative recurrence in Crohn's disease. Ann Surg 2000, $231: 38-45$.

46. Cosnes J, Nion-Larmurier I, Beaugerie L, Afchain P, Tiret E, Gendre J: Impact of the increasing use of immunosuppressants in Crohn's disease on the need for intestinal surgery. Gut 2005, 54:237-4l.

47. Present DH, Korelitz BI, Wisch N, Glass JL, Sachar DB, Pasternack BS: Treatment of Crohn's disease with 6-mercaptopurine. A long-term, randomized, double-blind study. $N$ Engl J Med 1980, 302:981-7.

48. Cosnes J, Cattan S, Blain A, Beaugerie L, Carbonnel F, Parc R, Gendre J: Long-term evolution of disease behavior of Crohn's disease. Inflamm Bowel Dis 2002, 8:244-50.

\section{FlOOOPrime
RECOMMENDED}

49. Markowitz J, Grancher K, Kohn N, Lesser M, Daum F: A multicenter trial of 6-mercaptopurine and prednisone in children with newly diagnosed Crohn's disease. Gastroenterology 2000, I I 9:895-902.

\section{FlOOOPrime}

\section{RECOMMENDED}

50. Picco MF, Zubiaurre I, Adluni M, Cangemi JR, Shelton D: Immunomodulators are associated with a lower risk of first surgery among patients with non-penetrating non-stricturing Crohn's disease. Am J Gastroenterol 2009, I04:2754-9.

\section{FIOOOPrime
RECOMMENDED}

5I. Lakatos PL, Golovics PA, David G, Pandur T, Erdelyi Z, Horvath A, Mester G, Balogh M, Szipocs I, Molnar C, Komaromi E, Veres G, Lovasz BD, Szathmari M, Kiss LS, Lakatos L: Has there been a change in the natural history of Crohn's disease? Surgical rates and medical management in a population-based 
inception cohort from Western Hungary between 1977 2009. Am J Gastroenterol 2012, 107:579-88.

\section{FlOOOPrime}

RECOMMENDED

52. Peyrin-Biroulet L, Oussalah A, Williet N, Pillot C, Bresler L, Bigard M: Impact of azathioprine and tumour necrosis factor antagonists on the need for surgery in newly diagnosed Crohn's disease. Gut 20II, 60:930-6.

\section{FlOOOPrime}

\section{RECOMMENDED}

53. Herrinton LJ, Liu L, Fireman B, Lewis JD, Allison JE, Flowers N, Hutfless S, Velayos FS, Abramson O, Altschuler A, Perry GS: Time trends in therapies and outcomes for adult inflammatory bowel disease, Northern California, 1998-2005. Gastroenterology 2009, 137:502-II.

\section{FlOOOPrime}

\section{RECOMMENDED}

54. Chatu S, Saxena S, Subramanian V, Curcin V, Yadegarfar G, Majeed A, Pollok R: OC-139 Time trends in rates of first surgical resection and thiopurine use in Crohn's disease: Retrospective Cohort Study. Gut 20I2, 6 I (Suppl 2):A60.

55. Present $D H$, Rutgeerts $P$, Targan $S$, Hanauer SB, Mayer L, van Hogezand RA, Podolsky DK, Sands BE, Braakman T, DeWoody KL, Schaible TF, van Deventer SJ: Infliximab for the treatment of fistulas in patients with Crohn's disease. N Engl J Med 1999, 340: 1398-405.

56. D'Haens G, Baert F, van Assche G, Caenepeel P, Vergauwe P, Tuynman H, de Vos M, van Deventer S, Stitt L, Donner A, Vermeire S, van de Mierop FJ, Coche JR, van der Woude J, Ochsenkühn T, van Bodegraven AA, van Hootegem PP, Lambrecht GL, Mana F, Rutgeerts P, Feagan BG, Hommes D: Early combined immunosuppression or conventional management in patients with newly diagnosed Crohn's disease: an open randomised trial. Lancet 2008, 37I:660-7.

\section{FlOOOPrime}

\section{RECOMMENDED}

57. Colombel JF, Rutgeerts P, Reinisch W, Mantzaris GJ, Kornbluth A, Rachmilewitz D, Lichtiger S, D'Haens G, Diamond RH, Broussard D, Hegedus R, van der Woude CJ, Sandborn WJ: P087 - SONIC: a randomized, double-blind, controlled trial comparing infliximab and infliximab plus azathioprine to azathioprine in patients with Crohn's disease naive to immunomodulators and biologic therapy. J Crohn's Colitis 2009, 3:S45-S46.

58. Griggs L, Schwartz DA: Medical options for treating perianal Crohn's disease. Dig Liver Dis 2007, 39:979-87.

59. Beaugerie L, Sokol H: Clinical, serological and genetic predictors of inflammatory bowel disease course. World $J$ Gastroenterol 2012, 18:3806-13.

60. Veloso FT, Ferreira JT, Barros L, Almeida S: Clinical outcome of Crohn's disease: analysis according to the vienna classification and clinical activity. Inflamm Bowel Dis 200I, 7:306-13.

61. Mekhjian HS, Switz DM, Melnyk CS, Rankin GB, Brooks RK: Clinical features and natural history of Crohn's disease. Gastroenterology 1979, 77:898-906.

62. Lakatos PL, Czegledi Z, Szamosi T, Banai J, David G, Zsigmond F, Pandur T, Erdelyi Z, Gemela O, Papp J, Lakatos L: Perianal disease, small bowel disease, smoking, prior steroid or early azathioprine/biological therapy are predictors of disease behavior change in patients with Crohn's disease. World J Gastroenterol 2009, I5:3504-10.

\section{FIOOOPRime
RECOMMENDED}

63. Pearson DC, May GR, Fick GH, Sutherland LR: Azathioprine and 6-mercaptopurine in Crohn disease. A meta-analysis. Ann Intern Med 1995, I 23:132-42.

\section{FIOOOPrime
RECOMMENDED}

64. Taxonera C, Schwartz DA, García-Olmo D: Emerging treatments for complex perianal fistula in Crohn's disease. World J Gastroenterol 2009, I 5:4263-72.

65. Dejaco C, Harrer M, Waldhoer T, Miehsler W, Vogelsang H, Reinisch W: Antibiotics and azathioprine for the treatment of perianal fistulas in Crohn's disease. Aliment Pharmacol Ther 2003, 18: I | 3-20.

\section{FlOOOPrime
RECOMMENDED}

66. Lecomte T, Contou J-F, Carbonnel F, Beaugerie L, Cattan S, Gendre J-P, Cosnes ]: Effect of azathioprine or 6-mercaptopurine on perianal lesions of Crohn's disease [Abstract]. Gastroenterology 2000, II 8:A785.

67. Bernell $O$, Lapidus A, Hellers G: Risk factors for surgery and recurrence in 907 patients with primary ileocaecal Crohn's disease. Br J Surg 2000, 87:1697-70I.

68. Sands BE, Anderson FH, Bernstein CN, Chey WY, Feagan BG, Fedorak RN, Kamm MA, Korzenik JR, Lashner BA, Onken JE, Rachmilewitz D, Rutgeerts P, Wild G, Wolf DC, Marsters PA, Travers SB, Blank MA, van Deventer S): Infliximab maintenance therapy for fistulizing Crohn's disease. N Engl J Med 2004, 350:876-85.

69. Bouguen G, Siproudhis L, Gizard E, Wallenhorst T, Billioud V, Bretagne J, Bigard M, Peyrin-Biroulet L: Long-term outcome of perianal fistulizing Crohn's disease treated with infliximab. Clin Gastroenterol Hepatol 2013, I I:975-8I.el-4.

\section{FlOOOPrime \\ RECOMMENDED}

70. Lémann M, Mary J, Colombel J, Duclos B, Soule J, Lerebours E, Modigliani R, Bouhnik Y: A randomized, double-blind, controlled withdrawal trial in Crohn's disease patients in long-term remission on azathioprine. Gastroenterology 2005, I 28:1812-8.

\section{FlOOOPrime
RECOMMENDED}

7I. Cassinotti A, Actis GC, Duca P, Massari A, Colombo E, Gai E, Annese V, D'Albasio G, Manes G, Travis S, Porro GB, Ardizzone S: Maintenance treatment with azathioprine in ulcerative colitis: outcome and predictive factors after drug withdrawal. Am J Gastroenterol 2009, 104:2760-7.

\section{FlOOPrime} RECOMMENDED

72. Subramaniam K, D'Rozario J, Pavli P: Lymphoma and other lymphoproliferative disorders in inflammatory bowel disease: a review. J Gastroenterol Hepatol 2013, 28:24-30. 